\title{
La construcción lógica de la Fenomenología del Espíritude Hegel
}

\author{
Diana María Lópež
}

Resumen: La Fenomenología del espiritu representa el punto de coronamiento de diversos proyectos elaborados por Hegel en los cursos de los años 1803-1807 del período de Jena. Así también, en algún sentido, la anticipación de su Lógica posterior. El artículo tiene como propósito dedicar algunas meditaciones básicas al origen de esta obra en relación con los cursos del período de Jena, la posible transformación conceptual de la Fenomenología durante el tiempo de su redacción y su contribución a la Ciencia de la lógica posterior.

Palabras clave: construcción lógica; Fenomenología del espiritu; sistema; ciencia; idealismo.

Abstract: The Phenomenology of Spiritis the crowning point of several projects elaborated by Hegel between the years 1803-1807, and anticipates in some sense his Science ofLogic. The aim of this paper is to lay out some basic meditations about the origins of this work in connection with the courses of the Jena period, the possible conceptual tranformations of the Phenomenology during the time devoted to its writing, and its links with Hegel's posterior piece of work, the Science of Logic.

Key words: logical construction; Phenomenology of Spirit, system; science; idealism.

* Doctora en Filosofía, Profesora del Profesorado y la Licenciatura de la Universidad Nacional del Litoral. Compiladora de Experiencia y limite. Kant-Kolloquium (2009), Experiencia y concepto. Hegel-Kolloquium (2011), Ser, razón y lenguaje. El problema de la universalidad y la cuestión del fundamento (2014) y Co-compiladora de El vuelo del búbo. Estudios sobre el idealismo 2014) y Verdad, lenguaje y acción (2014). Dirección electrónica: dianalopez@,bionik.tv 
El "Sistema de la Ciencia", bajo el cual concibe Hegel su filosofía entre 1804 y 1817, apenas dispone tras las clases de 1805/06 de otra realización objetiva que su introducción misma, la "Fenomenología del espíritu". Así pues, el sistema se desplaza hacia su comienzo en principio y de hecho. Desde que los esbozos de 1803/04 descubren la conciencia como núcleo de la filosofía del espíritu, éste deja de ser un círculo en que la unidad de cognoscente y conocido es la del conocer con lo que ello mismo era ya implícitamente; el conocimiento produce él mismo su propia naturaleza; la reflexión no sólo constata, sino que cambia su objeto, pues es negatividad, acción, experiencia práctica y no meramente contemplativa. Este artículo tiene como propósito reflexionar acerca de la génesis de la Fenomenología del espiritu ${ }^{1}$ en relación con los textos de los cursos de Hegel sobre Lógica y Metafísica del período de Jena, su posible transformación conceptual durante su tiempo de redacción y su contribución a la preparación del texto de la Ciencia de la lógica (1812-1816) en virtud de la estructura lógica que la sostiene en su monumental exposición dialéctica.

\section{Hacia el sistema de la ciencia}

La Fenomenología del espiritu apareció en el año 1807 bajo el título "Sistema de la ciencia. Primer tomo. La fenomenología del espíritu". El verdadero cuerpo de la obra se inicia con una reflexión, que al reaparecer en la edición de Obras completas apenas abarca trece páginas, siendo dotada aquí expresamente del título "Introducción"." Con ciertas reservas, podríamos denominar a esta reflexión "introducción", aunque este título falte en la primera edición. Ya en ésta se antepone un extenso Prefacio (WW II,3-

1 Publicada por primera vez como System der Wissenschaft. I. Theil Die Phänomenologie des Geistes. Bamberg-Würzburg 1807 y editada por Johannes Hoffmeister según el texto de la edición original, Leipzig,Félix Meiner, 1937, Introducción del editor, p. XXXVIII (Phä). Hay trad. esp. de W.Roces: Fenomenología del espíritu, México, F.C.E., 1966, que citaremos tras la paginación de la edición de Hoffmeister (Hamburg, 1952).

${ }^{2}$ Hegel, G.W.F. Werke (WW), Theorie Werkausgabe, a cargo de E. Moldenhauer y K.M.Michel, Frankfurt a. M., Suhrkamp, 1971, II a Jenaer Schriften, pp. 59-72.(Se basa en la edición de 1832-45, que, por otra parte, también reproduce la edición de $\mathrm{H}$. Glockner: Jubiläumsausgabe, Stuttgart, Frommann, 1927 ss.). 
58), que comprende cuarenta y una páginas. Después del Prefacio y antes de la "Introducción" se encuentra en algunos ejemplares de la primera edición una portada para todala obra con el título "Ciencia de la experiencia de la conciencia". Durante la impresión, Hegel reemplazó este título por el siguiente: "Ciencia de la fenomenología del espíritu". En la edición completa de sus obras, iniciada inmediatamente después de su muerte por sus discípulos, esta obra apareció en 1832 bajo el título de "Pbänomenologie des Geistes" (Fenomenología del espiritu). Este título es luego empleado por Hegel en la Introducción a la Lógicade 1812, cuando dice: "En la Fenomenología del espíritu he representado a la conciencia en su movimiento progresivo"(In der Phäenomenologie des Geistes habe ich das Bewuußtsein in seiner Fortbewegung) ${ }^{3}(S L$ 42;64). El artículo determinado y determinante "la" es dejado fuera. Puesto que poco tiempo antes de su muerte había comenzado a revisar esta obra, puede suponerse que la modificación del título, así como la incorporación del apartado "Introducción", corresponden a una decisión del propio Hegel.

La alteración del título originario tiene su explicación. La "Fenomenología del espíritu" debía perder el "rol" de "primera parte" del sistema porque "el sistema" mismo se había transformado en el pensamiento de Hegel. Para "elSistema de la ciencia", cuya primera parte la constituía la "Ciencia de la fenomenología del espíritu", estaba prevista una segunda parte, según un anuncio redactado porel mismo Hegelque aparecióel 28 de octubre de 1807 en el Jenaer Allgemeinen Literaturzeitung: "Un segundo tomo contendrá el sistema de la Lógicacomo filosofía especulativa, y de las restantes dos partes de la filosofía, las Ciencias de la naturaleza ydel espiritu".

De hecho, la anunciada Lógica "especulativa" comenzó a publicarse cinco años más tarde y precisamente bajo el título de "Ciencia de la lógica". El mismo corresponde al de la "primera parte" del "Sistema de la ciencia" de

${ }^{3}$ Hegel, G.W.F., Wissenschaft del Logik (WdL),Nürnberg,1812-1816. Zwei Bände. Auf del Grunslage der Werkevon 1832-1845 neu edierte Ausgabe Redaktion Eva Moldenhauer und Karl Markus Michel, Frankfurt am Main, Suhrkamp Verlag, 1969 (traducciónRodolfo Mondolfo, $\sigma^{a}$ reimp., BuenosAires., Solar, 1993; traducción Félix Duque, Madrid, Abada Editores, 2011). CitaremosSL, cuando se trate de la "Doctrina del ser" y WL, cuando las referencias correspondan a la "Doctrina de la esencia",seguido de número de la página. Los números después del primer punto y coma corresponden a la paginación de las ediciones españolas. 
1807: "Ciencia de la fenomenología del espíritu". Sólo que la "Ciencia de la lógica", en 1812, ya no aparece bajo el título abarcador "Sistema de la ciencia". Tampoco es yaeditada, correspondiendo al propio anuncio de 1807, como el "segundo tomo" o la "segunda parte" del sistema. En los años 1812 y 1813 verá la luz el primer tomo de la Lógica en dos libros, en los que está contenida la "Lógica objetiva"; en 1816 lo hará el segundo tomo, que concluye la obra con la "Lógica subjetiva" o la "Teoría del concepto". Las "Ciencias de la naturaleza y del espíritu", también previstas en el anuncio de 1807 para la segunda parte del "sistema", nunca aparecerán. Sabemos, por cierto, que durante su actividad académica en Jena (1801-1806) Hegel expuso detenidamente varias veces la Filosofía de la naturaleza y del espíritu. Fragmentos de esos cursos ingresaron en la "Fenomenología del espíritu", aunque con una función modificada. Por lo tanto, la publicación de las "Ciencias de la naturaleza y del espíritu" en la segunda parte del sistema de 1807 no se lleva a cabo. Un año después del acabamiento de la "Lógica", que había aparecido por sí misma entre 1812 y 1816, sin asignación expresa a un sistema como parte propia del mismo, Hegel publicó en el año 1817 su "Enciclopedia de las ciencias filosóficas en compendio. Para empleo en los cursos [del Dr. Georg Friedrich Wilhelm Hegel]". ${ }^{4}$

En este contexto, la lógica de Jena, la correspondencia, los cursos de Nürnberg (Jenenser Logik und Metaphysik, en adelante $J L M$ ) y, finalmente, la

${ }^{4}$ Hegel comenzó su actividad docente en el semestre de invierno 1816/17 en Heidelberg con el curso sobre la "Enciclopedia". La casi simultánea publicación de esta obra tiene sin duda su "motivación próxima" en la "necesidad" de poner en manos de los "oyentes un hilo conductor". Pero la razón interna de la publicación es la transformación del sistema en la forma que Hegel consideró definitiva y tambiénmantuvo como tal. En el Prefacio, dice: "En un compendio viene sin embargo entonces a consideración más bien sólo una conveniencia externa de disposición y organización, cuando hay un contenido ya presupuesto y conocido, que debe ser expuesto en una intencionada brevedad. En tanto la actual presentación no está en este caso, sino que expone una nueva elaboraciónde la filosofía según un método, el cual, como espero, será aún reconocido como el único verdadero, idéntico al contenido, entonces habría podido tener a la misma con respecto al público por más ventajosa, si las circunstancias me hubieran permitido hacer preceder un más detallado trabajo sobre las otras partes de la filosofía, semejante al que sobre la primera parte del todo, la Lógica, he entregado al público". 
publicación de la Ciencia de la lógica (Wissenschaft der Logik, en adelante $W d L)$ dan cuenta durante más de una década (1804-1816) del interés de Hegel por la lógica. Sin embargo, en este período se viene a intercalar, en 1807, la Fenomenología del espiritu. ${ }^{5}$

\section{Génesis, correspondencias y paralelismos}

La Pbä representa incontestablemente el punto de coronamiento de diversos proyectos de fragmentos de sistema elaborados por Hegel en los cursos de los años 1803-1807 del período de Jena, pero que vieron demorada su edición por hallarse inacabados o por ser estimados insatisfactorios por el autor. ${ }^{6} \mathrm{La}$ Phäaparece como la primera realización efectiva, cumpliendo y

${ }^{5}$ Por primera vez, en el semestre de verano de 1807, aparece bajo la pluma de Hegel, la expresión de "Fenomenología del espíritu". Así dice: "Logicam et metaphysicam, praemissa Phaenomenologia Mentis ex libro suiSystem der Wissenschaft, erster Theil; Philosophiam Naturae et Mentis". Es decir, que enseñará: "Lógica y Metafísica, teniendo como preámbulo una Fenomenología del Espíritu, a partir de su libro Sistema de la Ciencia; primera parte; la Filosofía de la Naturaleza y del Espíritu".

${ }^{6}$ En la edición de Gesammelte Werke de Hegel, publicada bajo la égida de la Academia de Ciencias de Renania-Westfalia, estos proyectos o esbozos de sistema de Jena corresponden a los tomos VI, VII, y VIII, editados bajo el título Jenaer Systementwürfe y bajo la responsabilidad de R.-P. Horstmann y J.H. Trede, Hamburg, Felix Meiner, 1971. Manuscritos conservados: 1) Vorlesungsmanuskripte über Logik/Metaphysik, Natur und Geistesphilosophie. Se han reencontrado los ms. del semestre de invierno de 1801/02: Introductio in philosophiam; cf. E.Ziesche, Unbekannte Manuskripte aus der Jenaer und Nürnberg Zeit in Berliner Hegel-Nachlass, Zeitschrift für Phil. Forschung 29 (1975), pp. 430-444; han sido utilizados por M. Baum y K. Meist en suDurch Philosophie leben lernen. Hegel-Studien,12(1977) y por M. Baum, Die Entstehung der Hegelschen Dialektik,Bonn, 1986, especialmente pp. 142-173. 2) Vorlesungsmanuskripte über Naturrecht (sólo fragmentos sueltos; en R. Haym, Hegel und Seine Zeit, Berlin 1857, pp. 159-167 y 414-416; especialmente importante es la llamada Fortsetzung des "Systems der Sittlichkeit”, publicada por Hoffmeister Dok., pp. 314-325). 3) Fragmenteaus Vorlesungsmanuskripten zur Philosophie der Natur und des Geistes (WS 1803/04), denominados por los editores de G.W. 6, Jenaer Systementwürfe I, K. Düsing y H. Kimmerle, comoDas System der speculativen Philosophie. 4)Logik, Metaphysik, Naturphilosophie. Fragment einer Reinschrift (WS 1804/05); en G.W. 7 (Jenaer Systementwürfe II). 5) Vorlesungsmanuskript zur Realphilosophie (WS 1805/06); en G.W.8 (Jenaer 
llevando a su término, la ambición afirmada en los textos de 1801 sobre la Differenz des Fichte'schen und Schelling'schen Systems der Philosophie, ${ }^{7} \mathrm{y}$ constantemente reiterada en este lugar, de una elaboración de la filosofía en la forma de una totalidad sistemática que presentó bajo el título de Primera parte del Sistema de la Ciencia. ${ }^{8}$

Systementwürfe III).La cronología de estos escritos ha sido fijada por Heinz Kimmerle: Zur Chronologie von Hegels Jenaer Schriften. Hegel-Studien (1967) pp. 125-176, y Die Chronologie der Manuskripte Hegels in den Bänden 4 bis 8 (enG.W.8, pp. 348-361). Un excelente estudio de conjunto sobre este período es el de H.S.Harris, Hegel's Development, II. Night Thoughts (Jena 1801/1806),Oxford, 1983 (el tomo I dedicado al joven Hegel: Towards the sunlight. 1770-1801, Oxford 1972); también consultar H. Kimmerle, Das Problem der Abgeschlossenheit des Denkens. Hegels 'System der Philosophie' in den Jahren 1800-1804, Bonn, 1970. Del tercer volumen hay traducción española por J.M. Ripalda: G.W.F. Hegel, Filosofía real, México, FCE, 1984.

${ }^{7}$ Hegel, G.W.F.: Differenz des Fichte'schen und Schelling'schen Systems der Philosophie, hrs.. von G. Lasson. Hamburg 1967 (Traducción española,Diferencia entre los sistemas de filosofía deFichte y Schelling, de María del Carmen Paredes Martín, Madrid, Tecnos, 1990).

${ }^{8}$ Este título conocerá, sin embargo, resoluciones diversas en el curso de la historia de las publicaciones hegelianas. Es conservado en los textos de presentación del primer libro del tomo I de la Wissenschaft der Logik consagrado a la lógica del Ser y publicado en 1812; en relación con la primera edición de la Enzylklopäedie der philosophischen Wissenschaften im Grundrisse, la Fenomenologíano es objeto más que de una breve alusión en el "Concepto preliminar", y siendo destituida de su función inicial por no devenir más que como un "eslabón orgánico en el círculo de la filosofía”.Cfr. Enæ;, 1827, \ 25N, traducción Ramón Valls Plana, Alianza, Madrid, 1999: "En mi Fenomenología del espiritu, la cual por esta causa, en su primera edición, fue rotulada como primera parte del sistema de la ciencia, se adoptó el camino de empezar por el primero y más simple fenómeno del espíritu, la conciencia inmediata, y de desarrollar su dialéctica hasta el punto de vista de la ciencia filosófica, cuya necesidad se muestra por este proceso". De hecho, Hegel lo sustituirá, en tanto que introducción a la ciencia, por las "Tres posiciones del pensamiento frente a la objetividad"; insistiendo en el carácter histórico y por así decir "exterior" de este texto. Pero, por otra parte, la Phäreaparece con su denominación original en la exposición del "Espíritu subjetivo", donde ella constituye el segundo momento (\$S 413-439), bajo una forma singularmente condensada y consagrada, por lo esencial, en las dos primeras secciones (conciencia y conciencia de sî), aunque no acordando con los dos parágrafos en la presentación de 
Si nos detenemos en la época de la edición de la obra de 1807, no podemos dejar de observar que esta publicación aparece en un contexto en el que predominan, por parte de Hegel, las preocupaciones y las reflexiones de orden lógico. De la Lógica de Jena, de la cual se sabe hoy que fue redactada en los años 1804-1805, a la "Doctrina del concepto", segundo tomo de la Ciencia de la lógica de 1816, habría en efecto un poco más de un decenio que Hegel consagra a la puesta a punto y a la elaboración definitiva de su lógica, especialmente entre 1808/1816, período este último que corresponde a la época de Nürnberg. ${ }^{9}$

En este contexto, estamos en condiciones de afirmar que el texto lógico más sistemáticamente elaborado poco tiempo antes de que su autor comience la redacción de la Phäes aquel de la Lógica de Jena (1804-1805) que, a pesar de algunos vacíos y lagunas, nos ofrece un testimonio preciso de la comprensión que Hegel tiene entonces de esta ciencia. El texto comporta tres partes. En la primera, lo que da en llamar larelación simple (Einfache Beriehung) englobará la cualidad, la cantidad, el quantum y acabará por el infinito. Es fácil presentir aquí algunas de las determinaciones principales que se explicitarán en la teoría del Serde 1812, por ejemplo, la categoría de "medida". Por su parte, lo infinito está definido en términos de contradicción absoluta, anticipando así directamente la conclusión del capítulo Fuerza y entendimiento (Kraft und Verstand) con el cual se concluye la primera sección de

la razón, en contraste con el amplio desenvolvimiento que se propone en la obra de 1807. Así, lejos de continuar representando una introducción a la ciencia, esta versión termina siendo, conforme a la exigencia formulada en la edición de 1817, una simple "malla orgánica o eslabón” del sistema enciclopédico; la exposición, en adelante, se subordina a las determinaciones del concepto y de la idea. En fin, a la vez que prepara una reedición de la Phä, poco tiempo antes de su muerte, Hegel estaría resuelto a suprimir definitivamente los subtítulos de la primera edición.

${ }^{9}$ Es justamente en estos cursos que dictará entre 1808 y 1811 a las clases superiores del Aegydius-Gymnasiumdonde asume otra dirección. Los mismosserán publicados bajo el título Propedéutica filosófica a partir de los manuscritos reunidos por Karl Rosenkranz en 1840. Hay traducción española: Propedéutica filosófica, traducción de E. Vásquez, Caracas, Equinoccio, 1980, y Doctrina del derecho, los deberes y la religión para el Curso Elemental, edición bilingüe, traducción de J. Navarro, Universidad de Murcia, 1993. 
la Fenomenología. ${ }^{10}$ En la segunda parte de esta Lógica de Jenase concentra la exposición de la relación (Verbältnis), considerada como el resultado de la superación (Aufhebung) de la relación simple que se desdobla en relación del ser y relación del pensar. En la primera se discriminan la relación de sustancialidad, de causalidad y de acción recíproca. Bajo esta denominación se indica luego el alcance de la herencia kantiana, dejando entrever las premisas de esto que constituirá, bajo el título de "Relación absoluta", lo correspondiente al último capítulo -"Efectividad"-en la futura Doctrina de la esencia(1813).En cuanto al pensar, tratará del concepto, del juicio y del silogismo, momentos que formarán posteriormente la primera sección de la Doctrina del concepto(1816). Por su parte, la tercera sección titulada Proporción, reúne la definición, la división y el conocer, es decir, algunos de los elementos que serán explicitados en la tercera y última sección de esta misma Lógica Subjetiva.Finalmente, en la Metafisicase distingue una Metafisica de la objetividad y una Metafísica de la subjetividad,para luego concluir en una presentación del espíritu absoluto. Todo esto lleva a inferir que, si bien la estructura es sensiblemente diferente a la de la futura Ciencia de la lógica,manifiesta bastante más que una mera similitud terminológica entre los nombres. En este contexto, es altamente significativo encontrar la primera formulación programática de la Phä: "La sustancia es más bien sujeto"."11

De este modo, si bien se puede constatar que se encuentra conservada la distinción entre Lógica y Metafísica a pesar del rol de término medio atribuido al conocer ("El conocer, en tanto que mediación en la Metafísica, está subsumido en la Lógica, ella misma entendida como dialéctica, en otras palabras como idealismo" ${ }^{12}$ y, que la noción de reflexión sigue muy cerca de la concebida en Glauben und Wissen y en el tratado sobre la Diferencia,estando, por ende, alejada aún de la auto-reflexividad que asumirá en el denso segundo capítulo de la Doctrina de la esencia (Wesenslogik) de 1813, se retendrá que la Lógica de Jena es ciertamente ya una lógica dialéctica. Ésta reúne todas las características de un proyecto preparatorio de lo que luego

${ }^{10}$ Logique et Métaphysique (Jena 1804-1805), G.W.VII, pp. 29-36. Cf. Phä, G.W.IX, pp.102-129; 82-104. Baste recordar que los puntos de este apartado en la Phäson nada menos que: "1. La fuerza y el juego de las fuerzas. 2. Lo interior. 3. La infinitud".

${ }^{11}$ Ibid. p. 140.

${ }^{12}$ Ibid. p. 127. 
hará eclosión en la Fenomenología del espíritu, independientemente de que aún no autorice a percibir de manera satisfactoria la presencia de lo que será el proceso de reconciliación y de reunificación de la conciencia y del concepto, tal cual concluirá la obra de 1807 . El concepto no es todavía reconocido en la plenitud de su función y de su sentido, plenitud en la cual no se encontrará hasta el Saber absoluto, deviniendo así el único objeto de esta ciencia pura del pensar que será lógica o filosofía especulativa.

Esto volverá definitivamente caduco todo proyecto de elaboración de una metafísica orientada a sostener la distinción entre sujeto y objeto: la conciencia accede al saber absoluto a partir de un auto-desenvolvimiento, de una auto-crítica, de una auto-disolución que ella presupone necesariamente es en este sentido que la dialéctica de las figuras de la conciencia descripta en la Introducción de 1807, corresponde rigurosamente a la definición que le da Hegel en los primeros pasajes de la Enciclopedia-. Sin embargo, las semejanzas entre los cursos de Jena y la Fenomenologíano autorizan a sostener idénticas similitudes con la futura "Lógica": la concepción y la organización estructural de la Ciencia de la lógica de Nürberg, sólo presenta aquí no mucho más que en estado germinal con bosquejos más o menos implícitos. Esto confirma y aclara la significación de las palabras de Hegel en sus cartas inmediatamente posteriores a la publicación de la Phä.La redacción de esta obra, comenzada en 1805, implica la presencia in mentis del autor de una lógica suficientemente diferente de la concebida hasta este momento. No se trata, por tanto, sólo de reformular para la imprenta una presentación sistemática e inmediata. La Phäapareceráen 1807, pero para la lógica objetiva habrá que esperar hasta 1812 y 1813 , y hasta 1816 , para la subjetiva.

A fin de esclarecer estas dificultades, se debe recordar la intención inicial que preside el proyecto hegeliano de redacción de una Fenomenología del espiritu: la ambición de exponer, explicitando rigurosamente las diferentes etapas, el camino de la conciencia natural elevándose al saber filosófico bajo el modo de una ciencia de la experiencia de esta conciencia: "Esta necesidad hace que este camino hacia la ciencia sea ya él mismo ciencia y sea, por ello, en cuanto a su contenido, la ciencia de la experiencia de la conciencia"(Phä 74; 60). 
En este contexto, Hegel no solamente habrá de afirmar y reconocer el derecho universal para toda conciencia humana de acceder al saber absoluto sino que forja los medios necesarios para llevar adelante este proyecto.

Dicho de otro modo, se esfuerza por elucidar las diferentes etapas por las cuales toda conciencia está en condiciones de elevarse de la simple certidumbre sensible -empíricamente la más rica y lógicamente la más pobre de todas las figuras de la conciencia- al saber absoluto, es decir, a la racionalidad identificada en el movimiento de la contradicción y en el proceso de interiorización conceptual de la articulación de estas experiencias. La Phätiene por blanco mostrar cómo, con aquel paso, por medio de aquellos recursos, la conciencia común, simple, natural e inmediata, es capaz de desprenderse de sus ilusiones sobre los objetos, sobre su mundo y sobre ella misma, para acceder al saber verdadero de este objeto y de sí misma por la mediación reflexiva y la apropiación de su propia historia ética, cultural y religiosa. Dice Hegel: “...lo sustancial del espíritu en general, es la esencialidad transfigurada, la reflexión que, siendo ella misma simple, es la inmediatez en cuanto tal y para sí, el ser que es la reflexión dentro de sí mismo. La ciencia, por su parte, exige de la autoconciencia que se remonte a este éter, para que pueda vivir y viva en ella y con ella" (Phä 25; 20).

Hegel logra así superar paso a paso todas las formas de dualismo que poseen los términos opuestos de la relación que los engendra y los hace vivir y progresar. La Phä aportará la prueba de su reunificación, reflexiva y negativamente advenida, y de su identificación diferencial, en el medio de un doble movimiento correlativo y recíproco de espiritualización de cada uno de los términos opuestos. ${ }^{13}$

13 Hegel anuncia para sus cursos a partir del semestre de invierno 1803-1804: Philosophiae specultativae systema, complectens a) Logicam et metaphisicam sive Idealismum trascendetalem, b) philosophiam naturae et c) mentis. Es decir, enseñará "el sistema de la filosofía especulativa”, el cual comprende a) la lógica y la metafísica, en otros términos, el Idealismo trascendental, b) la filosofía de la naturaleza y c) la filosofía del espíritu". Es probable que intente en este contexto, hacer de su lógica y de su metafísica reunidas, esa parte pura de la filosofía especulativa que Fichte y Schelling propusieron, el primero, en su Doctrina de la ciencia de 1794 y, el segundo, en su Sistema del idealismo trascendental de 1800. Con relación a sus primeros años en Jena, la posición 


\section{Texto fenomenológico y textos lógicos}

Esta génesis del proyecto de Hegel, conduce a enunciar tres consideraciones esenciales. La primera proveerá la explicación, en forma de confirmación, de esto que hemos dicho precedentemente, a saber, que la Pbä se erige en inventario a través de la sucesión de las figuras de la conciencia y del espíritu, de la inmensa riqueza cultural, ética y religiosa acumulada a lo largo de la historia del pensamiento, por lo que excede ampliamente su sólo status de introducción a la ciencia. La insistencia con la cual Hegel persigue el proyecto de una reedición mejorada de la obra de 1807, renunciando a su subtítulo, presenta como plausible tal hipótesis. La segunda consideración procede de la amplitud y complejidad del contenido que ella expone. Este no podrá ser inteligible más que por la puesta en obra más elaborada y suficientemente dominada de una infraestructura lógica sólo susceptible de asegurar la unidad del desenvolvimiento, el rigor del encadenamiento y la coherencia del sentido. Luego, una tercera consideración, es aquella que concierne directamente a nuestro propósito, y que plantea la cuestión de la naturaleza de la lógica interna que inviste el texto de 1807 a través de modalidades particularmente complejas, puestas de manifiesto en el propio desenvolvimiento del discurso fenomenológico.

Lo que revela este análisis del contenido es que, en el interior de una concepción sólidamente unitaria y coherente de la Fenomenología del espiritu, hay una maduración de la lógica que se encuentra subyacente. En este sentido, Pöggeler ${ }^{14}$ habla de una evolución de la concepción de la Phä en el curso de su redacción. Lo que evoluciona, en efecto, es la lógica de Jena, lo cual es el alma de la $P h a ̈$, y esta evolución se produce durante la redacción de esta obra y en ocasión de aquélla.

de Hegel se muestra aquí ya considerablemente evolucionada. Cfr. en este sentido, G. Schmidt, Hegel in Nürnberg. Unterschungen zum Problem der Pbilosophischen Propädeutik, Tübinguen, 1960.

${ }^{14}$ O. Pöggeler, "Die Komposition der Phänomenologie des Geistes", en Hegel-Studien, Beiheft 3 (1966), pp. 75-102. 
Un elemento a tener en cuenta a la hora de evaluar esta evolución es lo que en el capítulo VII de la Phä aparece más adelante como una presentación, desde el punto de vista de la conciencia, de la lógica del fenómeno. El descubrimiento del rol decisivo que juega el fenómeno para la lógica será lo que conduce a modificar el título de su obra y a no llamarla ya "Ciencia de la experiencia de la conciencia" sino "Fenomenología del espíritu". En todo caso, esta mutación implica una profunda evolución de la lógica hegeliana en dirección del sentido absoluto que pronto asumirá en el período de su madurez. En realidad, esto que Hegel había descubierto plenamente sin duda durante la redacción de la $P h a ̈$ es el punto de vista absoluto del concepto. Fenomenológicamente hablando, este descubrimiento se experimenta en la comprensión de la religión como conciencia de sí del Espíritu, lo que quiere decir que, más adelante para Hegel, la religión no será ya solamente una de las experiencias de la conciencia efectiva sino la conciencia de sí absoluta del Espíritu. La dualidad propiamente fenomenológica misma, más bien, fenomenal, en el sentido lógico más estricto, entre la conciencia mundana efectiva y la conciencia propiamente religiosa, se da en el capítulo VII sobre la religión manifiesta. Puesto que Hegel anticipa en el capítulo V las categorías lógicas que, en principio, habrán de estructurar los desarrollos del capítulo VII, es posible inferir que esta comprensión de la religión está ya presente en el espíritu de Hegel cuando redacta el capítulo correspondiente a la razón. Por otra parte, la invención de una lógica del fenómeno le permite, también en el capítulo VII, considerar las figuras de la conciencia mundana en las cuales es la esencia absoluta misma que se aliena (entäussert), como fenómenos o manifestaciones al servicio de la revelación del carácter absoluto del Espíritu. En consecuencia y por la misma razón, el capítulo VIII sobre el Saber Absoluto implicará una consagración a la metafísica de la subjetividad: el tono claramente fichteano (demasiado trascendental) de esta sección, donde el Espíritu absoluto aparece como la coronación del "Yo" teórico y del "Yo" práctico, es rebasado por una perspectiva que anuncia e imagina la absolutez de la lógica propiamente especulativa del concepto y de la Idea como unidad de la "Idea" teórica y de la "Idea" práctica. Esto explica el sentido del cierre del capítulo del Saber absoluto y de la Fenomenologíamisma, con la transcripción de los versos de Schiller:

"aus dem Kelche dieses Geisterreiches 


\section{La transfiguración de una escritura}

Antes de seguir adelante, conviene señalar las diferencias de escritura, de expresión y de procesualidad entre el texto fenomenológico y el de los textos lógicos correspondientes a los Jenaer Systementwürfe. El proyecto fenomenológico hegeliano, tal como lo caracteriza expresamente el Prefacio a la Fenomenología del espiritu, ofrece bajo un modo exotérico, público y abierto a todos, una visión de acceso a la verdad y al saber absoluto, es decir, a la filosofía entendida no más como simple amor al saber, sino como apropiación efectiva de ese saber por la conciencia (Phä12;9). Apelando al lenguaje como condición común del entendimiento universal, Hegel no se priva de utilizar todos sus recursos: metáforas, imágenes poéticas, ilustraciones literarias (Antífona, Hamlet, Don Quijote, el Sobrino de Rameau o Fausto) consideradas como las figuras ejemplares del propio devenir de la conciencia. Apostando a las infinitas posibilidades del discurso, sostiene una trama en la que se dan cita expresiones tan irónicas como provocativas destinadas a aprovechar los hábitos de habla en su recuperación para la construcción y transformación del sentido. En otras palabras, al mismo tiempo que una rigurosa dinámica regla la sucesión y el encadenamiento de las figuras, el lenguaje de la $P b a ̈$ se caracteriza por la concisión y no reniega de apelar cuando lo cree necesario, a la lengua popular. En este contexto, las dificultades de comprensión que pueden comprobarse, no tienden sino a sostener el sentido que se trata de transmitir: "El espíritu ha roto con el mundo anterior de su ser allí y de su representación y se dispone a hundir eso en el pasado, entregándose a la tarea de su propia transformación"(Phä 11;12).

A la inversa del discurso fenomenológico, el extremo rigor y densidad del discurso lógico encuentran su expresión apropiada en una escritura de un nivel elevado de abstracción, captando más de cerca su objeto, es decir, el movimiento del puro pensar. Las alusiones históricas y los ejemplos serán entonces marginados de un texto propiamente especulativo para ser recluidos a las observaciones o notas -explícitamente distinguidas de aquél- a fin de

15“... del cáliz de este reino de los espíritus rebosa para él su infinitud”(Phä 564; 473) 
reunir el pensamiento y el lenguaje representativo. A diferencia de la semántica fenomenológica, la austeridad de los textos lógicos puede a veces desanimar a más de un lector por la severidad estimada poco gratificante de lo "obligado del concepto". ${ }^{16}$

La apreciación diferencial de la procesualidad de las dos obras se presenta, de este modo, más clara. El discurso lógico se mueve en el elemento puro del pensar que es el concepto, y ninguna materia extraña vendrá a turbar e interrumpir su auto-desenvolvimiento. Dado que la disolución de la dualidad entre sujeto y objeto se produce al final del proceso fenomenológico bajo la forma de la libre reconciliación última de la conciencia histórica y del contenido absoluto de la conciencia religiosa, inviste al discurso lógico de la homogeneidad característica de la "unidad simple del concepto". Dice Hegel: Una vez que el espíritu ha alcanzado el concepto, despliega el ser allí y el movimiento en este éter de su vida, y es ciencia (Wissenschaft). En ella los momentos de su movimiento no se presentan ya como determinadas figuras de la conciencia (Gestalten des Bewußtseins), sino, en cuanto que la diferencia de la conciencia ha retornado al sí mismo, como conceptos determinados (bestimmnte Begriffe) y como el movimiento orgánico, fundado en sí mismo, de dichos conceptos"(Phä 562; 471).

\section{Círculo de círculos}

El tránsito lógico expone el proceso de engendramiento autodiferenciado del concepto según el movimiento dialéctico de la contradicción y tal que el todo está presente en cada uno de sus momentos, configurando así "un círculo de círculos cada uno de los cuales es un momento necesario, de tal manera que el sistema de sus elementos propios constituye la idea total, la cual aparece también de este modo en cada círculo singular". ${ }^{17}$ El movimiento de "lo lógico" no deja lugar para otra exterioridad que la que genera y para otra exteriorización que la que produce en un círculo que regresa a sí: "Éste es, dice Hegel, precisamente su único fin, su única actividad

${ }^{16}$ Ibid. Cfr. Pöggeler, O.,Hegels Jenaer Systemkonzeption, Philosophiches Jahrbuch, 1964, p. 300 .

${ }^{17}$ Enq, 1817, 』6, Nota, tomo I, p. 157; 1827-1830, \15, pp. 117,118. 
y meta, alcanzar el concepto de su concepto y lograr así el regreso a sí misma y su satisfacción"(En₹ $\left.\iint 17,117,118\right)$. El exterior no es ya lo que habría que unificar; es el pensamiento que se despliega, que se exterioriza en las significaciones que produce. Así la dimensión lineal y cronológica del texto recupera constantemente, a riesgo de las perturbaciones o de los ocultamientos, la organización estructural y el ordenamiento lógico progresando de manera circular. Ya nada será igual. El camino de la conciencia -de la certeza sensible al saber absoluto-, se eleva progresivamente a la ciencia, o lo que es lo mismo, al movimiento de la exteriorización en sí del concepto en el tiempo. Transido por una sucesión de figuras, surgiendo y desapareciendo por una necesidad interna, el todo no está ni en el comienzo ni en el resultado, sino en la articulación de conjunto del proceso por el cual ese resultado adviene en el pasado que retorna en sí, es decir, en su comienzo juicioso, reflexivo y reconocido como tal.

La expresión de este doble movimiento se encuentra en la distinción terminológica de las "figuras"y de los "momentos", las primeras de connotación más directamente histórica, las segundas en clara referencia a una significación eminentemente lógica. Si bien la aparición de esas figuras pone de manifiesto el carácter singular y puntualmente cronológico de la diversidad de las etapas por las cuales pasa el recorrido de la conciencia, dicho tránsito no puede explicarse más que por la referencia a una legalidad, a una medida, que sostiene el ritmo de su aparecer y la racionalidad de su marcha. Estas diferentes figuras -aquellas del amo, del esclavo, del estoico, del escéptico, de la conciencia desgraciada, etc.- se suceden "fenomenológicamente". No obstante cada una de ellas, encubriendo los elementos de universalidad e intemporalidad que transgreden la particularidad de su situación y le confieren un aspecto de permanencia, al mismo tiempo resurge y se recrea bajo otra figura, con otro rostro, en los otros niveles de desarrollo de la experiencia de la conciencia. ${ }^{18}$

A pesar del carácter sucesivo de este encadenamiento, cada figura revela por así decir un cierto aspecto de eternidad. Es en esta condición que

${ }^{18} \mathrm{Cfr}$. los paralelismos de estructuras y movimientos analizados por J.P. Labarriere en su obra Structures et mouvementent dialectique dans la Phénoménologie de l'Esprit de Hegel, Aubier, Paris, 1985. 
puede efectuarse -y se comprende- el pasaje, o más bien la transposición, de esto que adviene en esto que es, la historia "consumada"(Phä 434;402). En otras palabras, el texto hegeliano de 1807 despliega un contenido efectivo, de una diversidad, de una riqueza y de una complejidad excepcionales que lo sitúan al margen, no de la ciencia pura, sino de esas ciencias reales que son la Filosofía de la naturaleza y la Filosofía del espiritu. Aquello que confirmaron, como se ve posteriormente, las dos últimas ediciones de la Enciclopediaal insertar una Fenomenología del espiritu abreviaba en el proceso de la exposición del Espiritu subjetivo,es decir, en un momento de exteriorización y de efectuación del concepto y de la idea lógicos.

La pregunta que surge a continuación es: ¿cuál es el principio que asume la unidad del conocimiento en este proceso de exteriorización? La respuesta parece simple: ese proceso de desarrollo asegura él mismo la unidad del conocimiento, y por tanto, su totalización, puesto que este proceso es al mismo tiempo una reflexión del conocimiento sobre su propio trabajo, sobre la puesta a punto de sus significaciones. Manifestaciones de lo conocido y auto-referencia del conocimiento de sí mismo van de la mano. Esta respuesta nos conduce en adelante a la lectura interna de la lógica hegeliana que puede vislumbrarse en el propio corazón de la Fenomenología del espíritu en la especificidad y peculiaridad de su desarrollo.

\section{Desarrollo fenomenológico y coherencia especulativa}

Queda ahora interrogar sobre la naturaleza de los recursos lógicos de los cuales Hegeldisponeal momento de emprender la redacción de la Pbä, y bajo las modalidades según las cuales ellas estarían asegurando toda la progresión y garantizando la unidad y la coherencia. Al recuperar una analogía utilizada por Hegel mismo en la Introducción a la lógica del Ser en 1812, se podría decir que esta lógica se encuentra de algún modo presente y funcionando a la manera de la gramática del corazón de una lengua ( $W d \mathrm{~L}$ 27,28;206). A continuación, habremos de analizar la concepción que Hegel sostiene de la relación interna que une el discurso fenomenológico y las estructuras lógicas que lo ordenan y le dan sentido.

Comencemos por afirmar que la experiencia de la conciencia no revela ningún azar, ninguna arbitrariedad que le confiera el carácter de una iniciación 
secreta esotérica o edificante, sino al contrario, ella más bien procede de una necesidad interior expresiva del auto-desenvolvimiento del espíritu y garante del encadenamiento coherente y riguroso de todas las figuras que se suceden, de todas las experiencias que advienen para la conciencia y en las cuales ella reside antes de atravesarlas. Es decir, de todas las mediaciones que logra interiorizar hasta acceder al saber absoluto. Estas son las diversas modalidades, según las cuales opera esta necesidad interior, constituyendo la trama lógica de la Phäy confiriéndole ese carácter propiamente especulativo de sistematicidad y cientificidad.

La paradoja de esta conciencia sería su ceguera frente a la lógica que rige su propia experiencia y mediatiza desde el origen su relación con el objeto. La conciencia parece en efecto no recuperar más que el aspecto esencialmente negativo de su experiencia. Esto se traduce en el olvido o la ocultación de lo que no aparece sino hasta el final: la unidad en devenir de ella misma y de su objeto. Dice Hegel: “...el contenido de lo que nace ante nosotros es para ella, y nosotros sólo captamos el lado formal de este contenido o su puro nacimiento; para ella, esto que nace es solamente en cuanto objeto, mientras que para nosotros es, al mismo tiempo, en cuanto movimiento y en cuanto devenir"'(Phä 74; 60).

Ahora bien, la naturaleza del objeto que investigamos rebasa esta separación o esta apariencia de separación y de presuposición. La conciencia nos da en ella misma su propia pauta, razón por la cual la investigación consiste en comparar la conciencia consigo misma, ya que la distinción que se acaba de establecer recae en ella: "Hay en ella un para otroo bien tiene en ella, la determinabilidad del momento del saber"(Ibid.).

Liberado de las ilusiones que procedían de una oposición entre el sujeto y el objeto, la conciencia sabecomo inmediatamente idénticos la efectividad y su saber de sí mismo, de tal modo que el objeto, correlativo al movimiento de la conciencia, es el movimiento de determinación interna de sus propias diferencias, esto es, el espíritu. La gran división que habita la obra entre la "fenomenología de la conciencia" y la "fenomenología del espíritu", se ve resuelta en el propio proceso de su desarrollo para avanzar en orden a la aproximación de lo que constituye la verdadera mira del filósofo. 
A partir de esto, se comienzan a percibir más claramente algunas de las razones de la complejidad de la exposición fenomenológica. En la medida en que propone seguir y describir los caminos de la conciencia a través de las múltiples experiencias de la relación a su objeto, la lógica no interviene más de manera uniforme e idéntica, sino según las modalidades diferentes que a veces se recuperan y se entrecruzan en la ignorancia de la conciencia misma. Ignorancia que no impide su propia transformación operada al mismo tiempo por su objeto: esto que Hegel llama, "una conversión de la conciencia": "...punto en el que la manifestación se hace igual a la esencia y en el que, consiguientemente, su exposición coincide precisamente con ese punto de la auténtica ciencia del espíritu y, por último, al captar por sí misma esta esencia suya, la conciencia indicará la naturaleza del saber absoluto mismo" (Ibid.).

Se descubre aquí una lógica por así decir inmediata y lineal, que encadenará la sucesión de las figuras a la manera del tránsito exterior de una determinación a la otra anticipando la estructura de la futura lógica del Ser de 1812. En dirección a su destino, este movimiento cederá el paso a un proceso reflexivo y negativo de interiorización, de unificación y de totalización alcanzando su expresión en la forma del saber absoluto, es decir, en términos de racionalidad conceptual. Esto está dado claramente en el pasaje del Prólogo de la Phäque dice:

Este movimiento de las esencialidades puras constituye la naturaleza de la cientificidad en general. Considerado como la cohesión de su contenido, este movimiento es la necesidad y despliegue de dicho contenido en un todo orgánico. El camino por el que se llega al concepto del saber se convierte también, a su vez, en un devenir necesario y total, de tal modo que esta preparación deja de ser un filosofar contingente...(Phä 31, 25).

Esta lógica expansiva y mediatizante es la que permite operar la metamorfosis de la conciencia natural en saber absoluto, es decir, la transición, progresiva y verdaderamente dialéctica que procede superando las oposiciones e internándose en la esencia por un movimiento de reflexión a la vez circular y totalizante. Dice Hegel: "Al mostrar la sustancia perfectamente esto, el espíritu hace que su ser allí se iguale a su esencia; es objeto de sí mismo tal y como es, y se sobrepasa con ello el elemento abstracto de la inmediatez y la separación entre el saber y la verdad"(Phä 32; 26). Tal será esta lógica que 
trabaja por así decir "detrás y a espaldas" de la conciencia y que será sólo susceptible de inscribirse en el espacio inicial de la representación, como medio de esta "potencia absoluta" de lo negativo que constituye la actividad del entendimiento, al modo de las primeras y decisivas huellas del concepto. Es solamente así que puede ser realizado de manera completa, sistemática y científicamente, más aún, exhaustiva y auténticamente, este inmenso trabajo de mediación por el cual el desenvolvimiento de la conciencia finita genera enlazando y enlaza generando el proceso del espíritu apareciendo y elevándose hasta el saber absoluto de sí. "Su movimiento -destaca Hegel-, que se organiza en este elemento como un todo, es la Lógicao Filosofía especulativa”(Phä 33; 26). La confirmación será aportada ulteriormente, por el Prefacio de la primera edición de la lógica del Ser:

La conciencia, en cuanto espíritu que aparece y que se libera en su camino de su carácter inmediato y compacto, viene a ser saber puro, que tiene por objeto aquellas esencialidades puras mismas (reinen Wesenheiten), tal como en y para sí son. Ellas son los pensamientos puros, el espíritu que piensa su propia esencia. El automovimiento de esos pensamientos es su vida espiritual, y es aquello por lo cual se constituye la ciencia y de lo cual es ella exposición" ( $S L$ $17 ; 39 ; 186)$.

El estatuto y la función de la lógica en el interior de la Phä reviste, en este contexto, la extrema complejidad que explica la dificultad de la comprensión del texto. Ella se encuentra en situación ambivalente, puesto que está a la vez presente en sí y ausente para sí. Puede ser la conciencia de esta complejidad la que conduce a Hegel a dirigir los señalamientos que jalonan, de manera puntual y fragmentaria, el curso de la experiencia de la conciencia. La intervención del para nosotros (Für uns) correspondiente a los incisos de amplitud desigual, que parece suspender momentáneamente el desarrollo del proceso fenomenológico para insertar consideraciones de orden estructural o lógico destinadas a señalar un desvío, intentan completar la mirada del lector entre el para sí de la conciencia y el momento en el cual se ve alcanzado el desarrollo del espíritu. ${ }^{19}$ Esta presencia, más o menos discreta

${ }^{19}$ En su artículo "Für uns en la Phä", Archives de Philosophie,oct.-dic. 1970, pp. 829-854, Joseph Gauvin realiza un inventario exhaustivo de las diversas apariciones de para nosotros en la obra de 1807. Según Gauvin, la variación funcional de esta locución, se 
e insistente del para nosotros, que sutil pero eficazmente "sostiene" la trama continua del discurso fenomenológico, apunta a establecer las líneas entre dos experiencias diferentes, disyuntivas y alejadas. Puede actuar, sea en pasajes que retrasan o recapitulan diversas frases del proceso, sea anunciando anticipaciones de desenvolvimientos por venir, pero que se originan ya en aquel momento alcanzado.

Curiosamente $-\mathrm{y}$ paradójicamente- la intervención del para nosotros, se asemeja a un discurso de exterioridad que parece no interferir con el encadenamiento sucesivo de las figuras para insertar solamente a la manera de un paréntesis, aquello que nos brindan las indicaciones procesuales o estructurales extremadamente precisas sobre la organización y el funcionamiento de los indicadores de sentido más interiores, más profundos de la Phä.

La infraestructura lógica es esto que asegura los progresos de la conciencia y del saber que adquiere de ella misma y de su objeto. Lo que la conciencia se ve obligada a abandonar detrás de ella, o por y en la medida de su metamorfosis, no es ni definitivamente perdido ni anulado pues la dialéctica no es un escepticismo generalizado, sino, por el contrario, lo que permite reinscribir continuamente y de manera renovada, las diferencias en el proceso de identificación conceptual, garantizando así no solamente el engendramiento de sentidos sino su profundización y su enriquecimiento. Dado que el progreso no es acumulativo sino cualitativo, cada vez, una nueva figura de la conciencia emerge de experiencias y travesías. En efecto, paradójicamente, esta conciencia no es la misma que parece que reencuentra, pone y reconoce su otro como otro en tanto que tal. El acceso de la conciencia al saber absoluto está así asegurado por esta compleja imbricación entre el esquema lineal de la sucesión de figuras, de una parte, y el esquema lógico, reflexivo y circular, de la inmediatez primera, de la negación mediatizada y mediatizante y de la inmediatez devenida, de la otra.

corresponden con el rigor y la sistematicidad que el autor caracteriza así: "Las intervenciones de esta locución constituyen los elementos de un sistema de diferencias que se ponen y se completan, midiendo una progresión o incorporando en realidad la modalidad de una progresión". 


\section{Conclusión}

La originalidad de la Fenomenología del espiritu, más allá de constituirse en una "introducción" que opera como primera parte del sistema y, por lo tanto, como proceso autodestructivo de todas las formas y grados de certeza limitada, radica en la lógica del devenir de lo que aparece en tanto aparece, lo cual consiste en una auténtica creación de sentido en tanto re-configuración de lo real. Precisamente, si la idea de la Fenomenologiasurge del intento de agotar la serie de las "figuras de la conciencia" hasta llegar a la "verdadera experiencia", lo que muestra este desarrollo es que la figuras dicen precisamente por acoger lo que viene dándose en su ser hacia. Momento y tensión, las figuras se muestran contra la precipitación de la insaciable sed de una solución final: saber.

A medida que va dejando tras sí su apariencia como conciencia y como autoconciencia (incluyendo también la "reconocida" autoconciencia del "nosotros"), se hace patente un movimiento que, en su verdad, no puede sino configurarse como determinación interna de sus propias diferencias, de allí que carezca de sentido cegarse ante la indudable riqueza y colorido de cada una de las figuras, detenerse como si fuera el último en cada uno de sus momentos, pues, más allá de estas configuraciones, se trata de atender a la totalidad en juego que se juega como una vida que se ordena hacia el todo: no cabe leer entonces las figuras como meros mojones en la pura sucesión que conduciría de lo universal a lo singular y en el simple retorno de la vida del espíritu captado como totalidad.

En este contexto, la presencia de lo lógico en el corazón mismo de la Fenomenologiaimpide una simple lectura en la que, con la perspectiva de un itinerario que recorrer, todo quedara reducido a que las etapas sucesivas se encadenan progresivamente, sobrepasando lo alcanzado y enlazando un punto de partida y un final -ambos supuestamente exteriores el uno del otro. De lo que se trata, más bien, es de atender a la presencia de la vida del espíritu captado como totalidad en cada una de las etapas. Por ello, únicamente resulta una lectura conceptual de las figuras mediante una interiorización y profundización que sólo es capaz de efectuarse desde ese todo que se despliega sin fijarse -quedarse fijado- en las formas que asume, a fin de recapitular sus momentos. El espiritu, al efectuar esta recapitulación, se re-crea 
en los resultados impidiendo que éstos sean tomados por definitivos. El todo no logra su plena culminación (Vollendung) ni es algo al margen de la totalidad del movimiento -su movimiento- que lo considera como todo.

Este momento de "reunión", último capítulo de la Fenomenología,es a su vez comienzo. Este comienzo descansa en el resultado de las experiencias de la conciencia, la cual se inicia con la certeza sensible y llega a su culminación en lo que Hegel denomina "saber absoluto": aquí es donde por primera vez, comienza la ciencia, porque aquí es donde por primera vez no hay nada más que los pensamientos, esto es, no es pensado nada más que el concepto puro en su pura determinación.

Lo que aquí se "suprime", se "levanta", es la diferencia entre el saber y la verdad propia de la Fenomenología.Este"movimiento en cuyo trascurso se supera dicha diferencia" da paso a "la pura figura del momento liberada de su manifestación (fenoménica) en la conciencia", al "puro concepto y su progresión", el cual dependerá ahora "solamente de su pura determinación" (Phä 562; 472). En la Fenomenología, la experiencia -que es dialéctica- aparece como una oscilación entre una verdad que sería extraña a la certeza y una certeza subjetiva que no tendría verdad; en la Lógica, la experiencia como tal es superada y la verdad misma es la que se desarrolla en sí y para sí, pero a esta verdad es inmanente la certeza de sí y, justamente, "esta mediación simple, esta unidad, es lo que constituye el concepto". Si, como dice Hegel,"la forma del concepto reúne en una unidad inmediata la forma objetiva de la verdad y la del sí mismo que sabe" (Idem), ${ }^{20}$ dicha unidad es el resultado de la Fenomenología al tiempo que el presupuesto de la Lógica o filosofía especulativa. Pero nada se sabe si no está en la experiencia. El saber empírico, la experiencia en general con su desarrollo es en la Fenomenología, el Fenómeno del Saber Absoluto en tanto que aparece, y sólo es fenómeno en tanto que no sabe todavía que es él mismo el que se aparece a sí mismo, que su aparición es la conciencia de sí universal. Siguiendo a la conciencia fenoménica en su itinerario, la conciencia filosófica que ya ha recorrido el camino, muestra que

20 Puede compararse lo que hemos denominado "Génesis fenomenológica del concepto" (II Parte) con la lógica objetiva (ser, esencia), que es una génesis ontológica del concepto. 
el saber absoluto se trasluce ya en la experiencia, pero que sólo lo es cuando ella se sabe como saber absoluto.

El saber es ahora absoluto, pero ni el saber puede ser entendido como pura interioridad nocional al margen de su efectuación histórica -una especie de teoría pura- ni lo absoluto, que lo califica, como una suerte de perfección o acabamiento, una plena culminación en el aquí y en el ahora de todas las formas posibles de conocer y de obrar. El conocer (tener conciencia de algo distinto al ser consciente, cognoscente) ha ido quedando superado (y a la vez conservado) en el saber, esto es: en la acción de reconocimiento de la mismidad de la conciencia y su objeto, al punto que la "cosa sabida" ya no es sólo para nosotros, sino que es también "en y para sî". "El espíritu quese manifiesta en este elemento ${ }^{21}$ a la conciencia 22 o, lo que aquí es lo mismo, que es aquí producido por ella, es la Ciencia"(Phä 556; 467).

A lo largo de los años de Jena, Hegel no sólo revisa la concepción sustancialista de su primera doctrina, sino que integra de una manera protagónica al mismo filósofo: su inmanencia en el sistema, la génesis histórica de su pensamiento y con ello el lugar de lo individual y variable en el despliegue de los momentos singulares "cada uno de los cuales presenta en su principio la vida del espíritu todo"(Phä, 556; 466).

El espíritu no finge estar enajenado. Sólo sabe lo que es en cuanto atiende a su ir sabiendo lo que va siendo: de aquí la originalidad provocadora y estimulante de este "viaje de descubrimientos" que es la Fenomenología del espiritu. Porque saber no es sino la propia inquietud de saber que lleva a ir más allá, no como salir sino como desplegar las propias posibilidades, como un ir dentro de sí (Insichgehen) del espíritu mismo. La inquietud constitutiva y estructural del espíritu, su insatisfacción, su deseo de realizar y revelar lo que

${ }^{21} \mathrm{El}$ elemento del "estar ahí", aquello en que se mueve la existencia óntica, no es ya tan sólo una "cosa" o sustancia, sino también sujeto: es la forma de la objetividad para la conciencia, la esencia absolutamente conformada. A esto lo llama Hegel: "concepto"(Begriff).

22 Adviértase que tampoco en el Saber absoluto queda la conciencia "superada": la Ciencia es para ella (que también somos ya "nosotros"), no para sí. Por eso aparece la Ciencia en forma de Saber. Y por eso no basta con la Fenomenologíay hay que pasar a la Lógica. 
es, es la de acceder a una exteriorización realmente (wirklick) interior. Sabe absolutamente su necesidad constitutiva. Sólo dice lo que es en el movimiento de retornar a sí (in sich zurückgehende), al exponerse (sichdarstellen) y arriesgarse plenamente.

Recibido:9/2015; aceptado: 11/2015 